\title{
Controversial Issue in Water Birth to Reduce Perineal Trauma
}

\author{
Surahman Hakim ${ }^{1}$, Budi I Santoso ${ }^{2}$, Ali Sungkar ${ }^{3}$, Raymond Surya ${ }^{4}$, Adly N Al Fattah ${ }^{5}$
}

\begin{abstract}
Introduction: Perineal trauma becomes a concern during childbirth. One method to reduce perineal trauma is through water birth; however, there is still a lack of publication about water birth. This study aims to appraise the benefit of water birth to reduce the perineal trauma.

Materials and methods: Searching was conducted on Pubmed ${ }^{\circledR}$, Cochrane Library ${ }^{\circledR}$, and Medline ${ }^{\circledast}$ using keywords or MeSH. There were 4 eligible articles consisting of 1 case-control, 1 clinical trial, and 2 systematic reviews. Appraisal determining the validity, importance, and applicability (VIA) was conducted by two independent authors guided by British Medical Journal (BMJ) Evidence-based Medicine Toolkit.

Results: There were no difference percentage of intact perineum (RR 1.16; 95\% Cl 0.99-1.35), episiotomy (RR 0.93; 95\% Cl 0.80-1.08), second degree tear (RR 0.94; 95\% Cl 0.74-1.20), and third/fourth degree tear (RR 1.37; 95\% Cl 0.86-2.17) between water birth and conventional birth in a systematic review. Another review showed that water birth decreased the use of episiotomy and the severity of perineal laceration. A prospective trial study concluded that water birth caused less requirement for obstetric intervention; however, it impacted to more perineal laceration. Another study showed lower episiotomy and higher intact perineum rates in water birth group.

Conclusion: There is still inconsistency of water birth in reducing perineal trauma.

Keywords: Episiotomy, Perineal trauma, Water birth.

Journal of South Asian Federation of Obstetrics and Gynaecology (2019): 10.5005/jp-journals-10006-1688
\end{abstract}

\section{INTRODUCTION}

Perineal trauma, especially 3rd and 4th degree of obstetrical anal sphincter injury (OASIS), becomes a concern during childbirth. Approximately $85 \%$ of women in UK experienced some degrees of perineal trauma during delivery. ${ }^{1}$ The incidence of perineal trauma varies among studies; there was a decline from $4.03 \%$ in 2002 to $1.17 \%$ in 2007 in the proportion of women with anal sphincter injury in Norway. It was because the program of slowing the delivery of infant's head and instructing the mother not to push before the second stage of labor. ${ }^{2}$

Obstetrical anal sphincter injuries (OASIS) has an association with short- and long-term of maternal morbidity such as anal incontinence, urinary incontinence, and sexual dysfunction. This morbidity impacts to the quality of life. Several risk factors increased the incidence of OASIS, including forceps, a longer duration of second stage of labor, nulliparity, large for gestational age or birthweight, occipitoposterior (OP) position, and episiotomy. ${ }^{3,4}$

One method to reduce the length of labor and perineal trauma is through water birth; however, there is still a lack of publication about water birth. In 1983, Michael Odent published in 100 water births for the first stage of labor to reduce the need for intervention and analgesia. ${ }^{5}$ Water birth is defined as fetal delivering underwater and it differs from immersion hydrotherapy; however, the safety and benefits of water birth is still controversial. ${ }^{6}$ Water birth is related to improved uterine perfusion, less painful contractions, and a shorter labor with lesser interventions. ${ }^{7}$

In US hospitals, the water-birth procedure is still limited when compared with other developed nations. Meanwhile, most hospitals in the United Kingdom and more than one-quarter of European hospitals in German-speaking regions provide water birth to healthy women. ${ }^{8}$ The Royal College of Obstetricians and Gynecologists (RCOG) recommends water birth as a birthing option, which should be offered to healthy women with uncomplicated pregnancies. ${ }^{6}$ There are some serious complications related to
${ }^{1-5}$ Department of Obstetrics and Gynecology, Dr Cipto Mangunkusumo Hospital, Jakarta/Faculty of Medicine, Universitas Indonesia, Jakarta, Indonesia

Corresponding Author: Raymond Surya, Department of Obstetrics and Gynecology, Dr Cipto Mangunkusumo Hospital, Jakarta/Faculty of Medicine, Universitas Indonesia, Jakarta, Indonesia, Phone: +62 81320000288, e-mail: raymond_s130291@yahoo.co.id

How to cite this article: Hakim S, Santoso BI, Sungkar A, et al. Controversial Issue in Water Birth to Reduce Perineal Trauma. J South Asian Feder Obst Gynae 2019;11(3):207-211.

Source of support: Nil

Conflict of interest: None

water birth such as neonatal drowning, transmission of waterborne infectious disease, cord rupture, and neonatal death. ${ }^{9}$

In Indonesia, the practical data about water birth are unknown and this procedure is still not legally accepted by Indonesian Obstetrics and Gynaecology Association (Perkumpulan Obstetri Dan Ginekologi Indonesia). Therefore, this study aimed to appraise the benefit of water birth in labor to reduce the perineal trauma.

\section{Materials and Methods}

To answer the clinical question, a search was conducted on Pubmed $^{\circledast}$, Cochrane Library ${ }^{\oplus}$, and Medline ${ }^{\oplus}$. In PubMed, the search included keywords using the MeSH, namely "Pregnant Women" AND "Episiotomy" OR obstetric anal sphincter injur* OR perineal laceration AND water birth. Meanwhile, in cochrane, the MeSH descriptor consisted of (pregnant women) and (episiotomy) or obstetric anal sphincter injury* or perineal laceration and water birth or immersion water birth, and conventional vaginal delivery. The author used keywords of pregnant women AND water birth AND obstetric anal sphincter injury OR episiotomy AND conventional birth in Medline. In the searching strategy performed 
on November 1 2017, there were 10,128, and 3 studies in Pubmed ${ }^{\circledR}$, Cochrane Library ${ }^{\circledR}$, and Medline ${ }^{\circledR}$ database, respectively. The articles were screened using the criteria consisting of abstracts answering the clinical question, written in English language, fulltext paper availability, and omitting all duplication papers. After screening, there were 4 articles inappropriate to the inclusion criteria consisting of 1 case-control, 1 prospective clinical trial, and 2 systematic reviews. Critical appraisal determining the validity, importance, and applicability (VIA) was conducted by 2 independent authors. The critical appraisal steps used in this article were written by Karen et al., ${ }^{10}$ Leyla et al., ${ }^{11}$ Elizabeth et al., ${ }^{12}$ and Elizabeth et al. ${ }^{6}$ The searching strategy was shown in Flowchart 1.

\section{Results}

Of the 4 studies appraised, all studies in appropriate with VIA criteria based on critical appraisal of therapeutic study and systematic review by Centre for Evidence-Based Medicine, University of Oxford, 2010. Systematic reviews by Elizabeth et al. ${ }^{12}$ and Elizabeth et al. ${ }^{6}$ showed patients-intervention-comparison-outcome (PICO) and inclusion criteria were in line with the aim of this study. Besides, in two systematic reviews, the studies used were valid enough and they figured out similarity result. Meanwhile, of therapeutic appraisal form, two studies did not show randomization and keep blinding for treatment. For importance, both studies did not reveal the precise effect. Meanwhile, only Karen et al. ${ }^{10}$ study had similar characteristics with our patients. Tables 1 and 2 showed the result of appraisal between systematic reviews and therapeutic studies.

\section{Discussion}

Hydrotherapy of water birth offers several positive physiological effects, including buoyancy, hydrostatic pressure, and related to thermal changes. The buoyancy is believed to ease the women delivering because it facilitates the neurohormonal interactions of labor, decreases the pain, and optimizes the progress of labor. ${ }^{13}$ In addition, water immersion can improve the uterine perfusion, lead to the less painful contraction, and resulted in a shorter labor with fewer intervention. ${ }^{8,14}$

Elizabeth et al. ${ }^{6}$ revealed that there was no significant different for the outcome of perineal trauma such as intact perineum (RR 1.16; 95\% Cl 0.99-1.35), episiotomy (RR 0.93; 95\% Cl 0.80-1.08), second degree tear (RR $0.94 ; 95 \% \mathrm{Cl} 0.74-1.20$ ), and third/fourth degree tear (RR 1.37; 95\% Cl 0.86-2.17) between control and waterbirth group. Even though, they admit that the overall studies had high heterogeneity. Latter systematic review by Elizabeth et al. ${ }^{12}$ showed that water birth decreased use of episiotomy and it reduced the incidence and severity of perineal laceration. In addition, the risk of severe laceration was lower in the water birth group compared to the conventional group. Unfortunately, episiotomy had not been consistently controlled in analyses. They analyzed through included studies, the rate for first or second-degree laceration was consistent; meanwhile, it was not shown in third or fourth-degree laceration. Study by Cortes et al. ${ }^{15}$ found that there was an increased incidence for third-degree laceration in water birth rather than conventional birth $(2.5 \%$ vs $1.2 \% ; p<0.005)$; however, episiotomy incidence and neonatal weight were not controlled in analysis. Therefore, perineal trauma in water birth still lacks consistency in this systematic review.

A study by Leyla et al. ${ }^{11}$ concluded that water birth caused less requirement for obstetric intervention such as induction and episiotomy; however, it impacted to more perineal laceration. They figured out that the laceration in water birth was less severe than in epidural analgesia or conventional delivery group. In water birth, the birth attendant is difficult to assess the perineum during labor so that it causes more perineal trauma. Another study in Singapore stated that lower episiotomy and higher intact perineum rates were shown in the water birth group. All women in the water group had written birth plan to delivery for minimal intervention such

Flowchart 1: Searching strategy

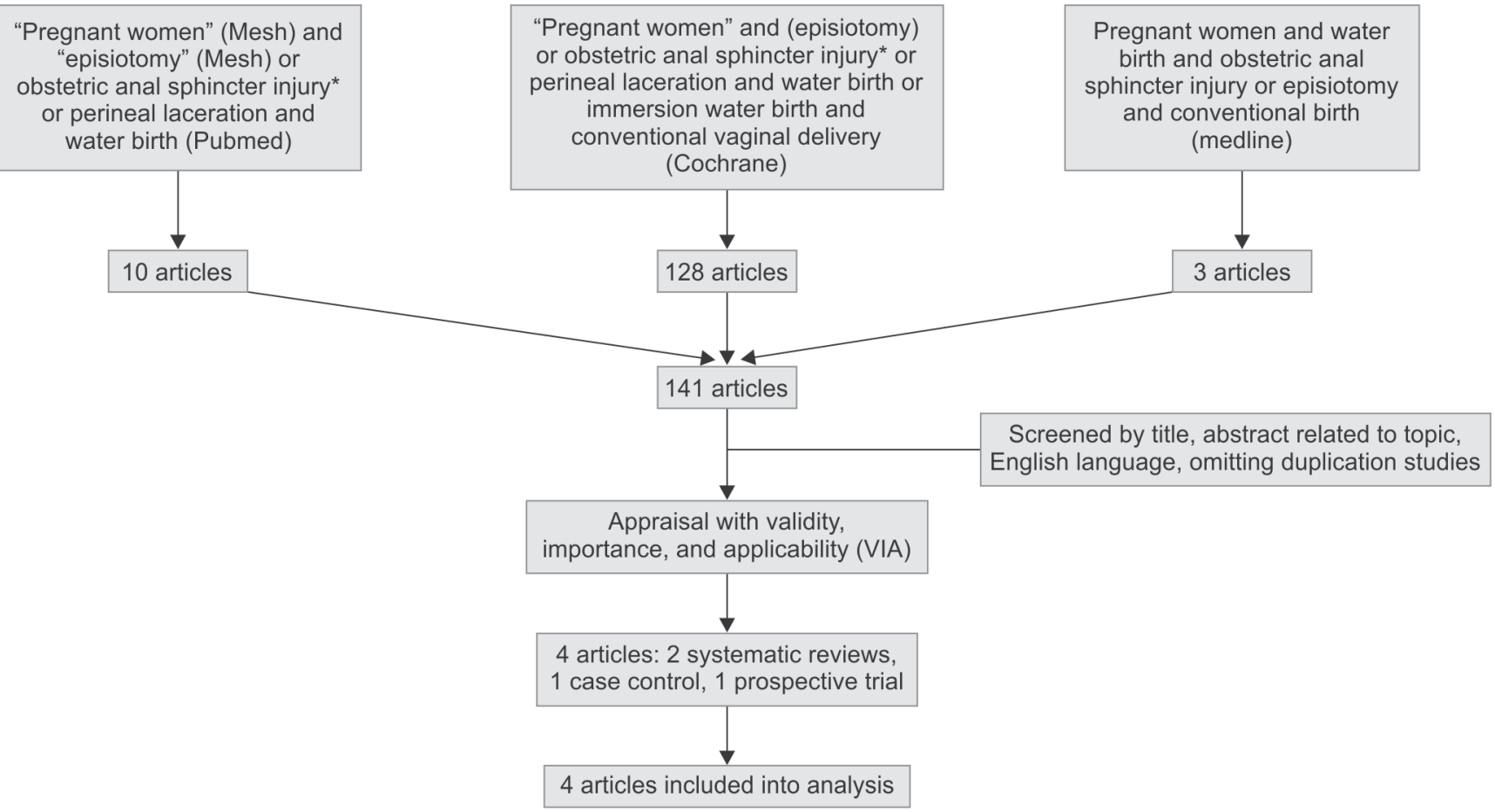




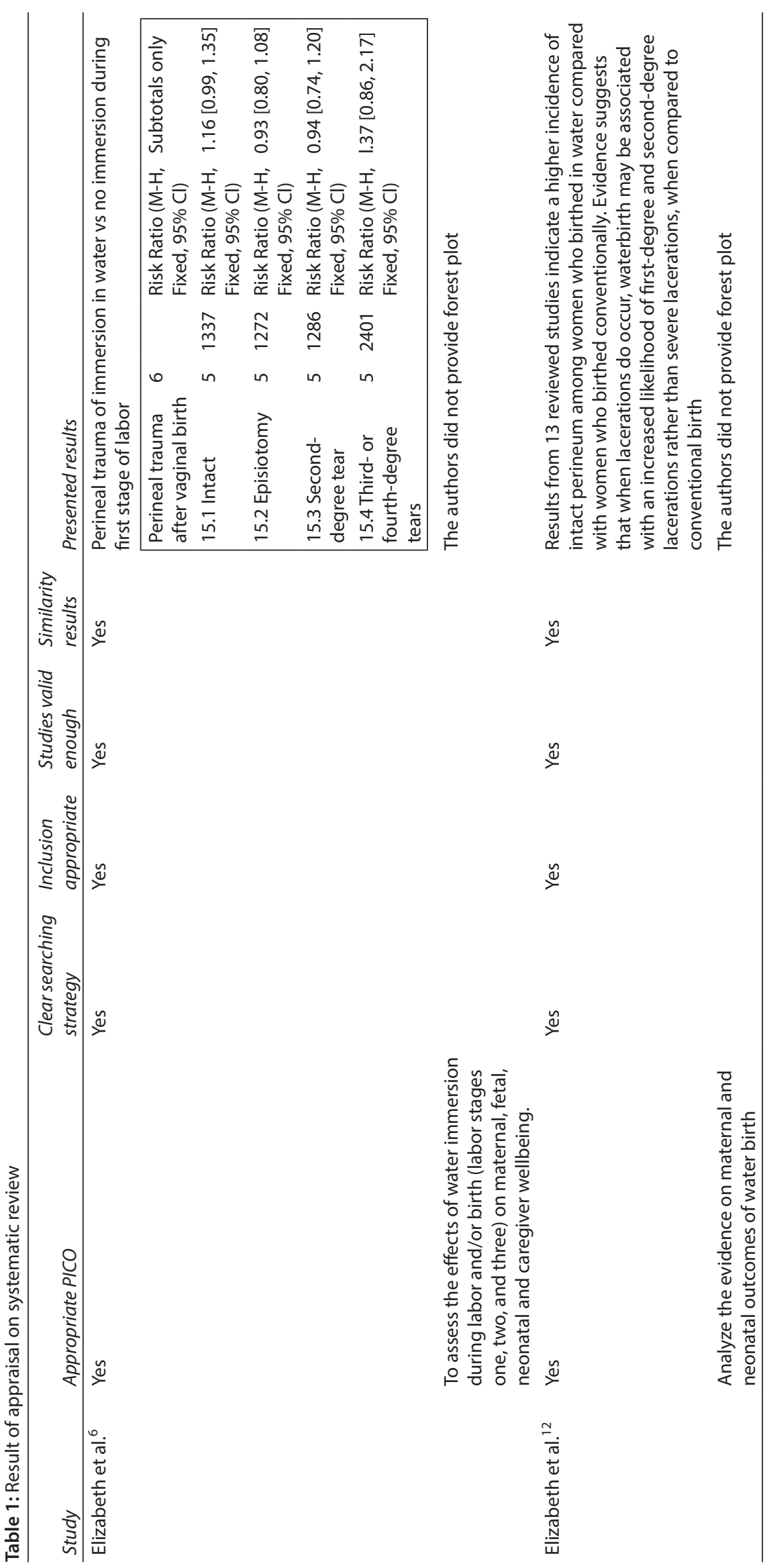




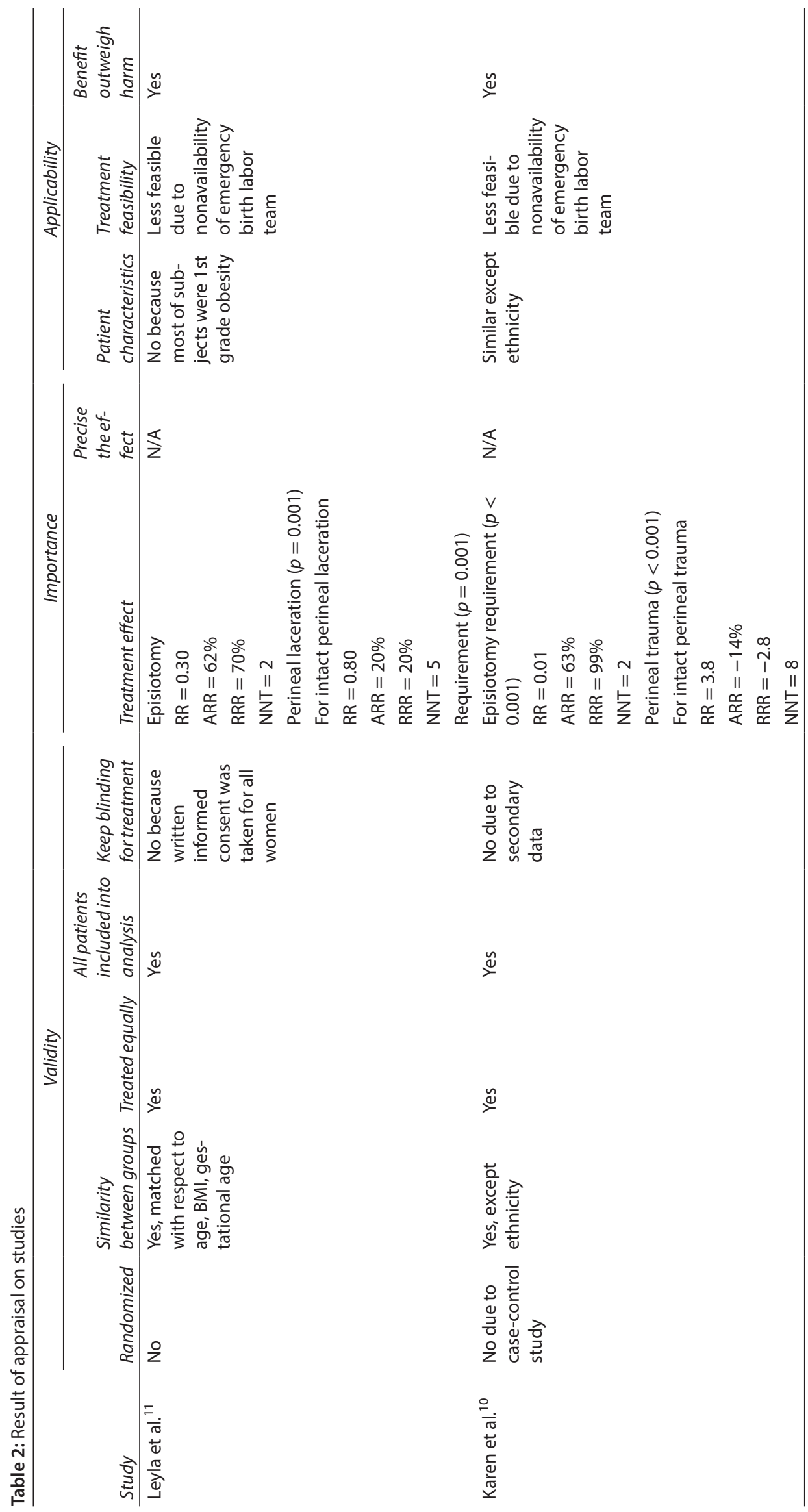


as episiotomy. Meanwhile, in hospital that study was held out, the episiotomy was almost a routine procedure for all nulliparous women to minimalize the third and fourth-degree tear. ${ }^{10}$ Therefore, this study should be re-evaluated for the necessity of conducting episiotomy prophylactically in their practice.

Of all studies appraised above, the need of episiotomy was lower in water birth although the rates of perineal tear were so varied among studies. The limitation among studies is about the blinding to intervention. Blinding is almost impossible for this case because the method of delivery is an option for every pregnant woman. ${ }^{6}$ The benefit for water birth for reducing obstetric intervention and perineal trauma should be reevaluated by adjusting the several risk factors, including parity, neonatal birth weight, and duration of the second stage of labor. We suggest that application of the practice of water birth in Indonesia needs more preparation in terms of facility, health providers, and clinical training.

\section{ConcLusion}

There is still inconsistency of water birth in reducing perineal trauma.

\section{References}

1. Kettle C, Tohill S. Perineal care. BMJ Clin Evid 2008 Sep 24;2008:1401.

2. Hals $E$, Oian P, Pirhonen T, et al. A multicenter interventional program to reduce the incidence of anal sphincter tears. Obstet Gynecol 2010 Oct;116(4):901-908. DOI: 10.1097/AOG.0b013e3181eda77a.

3. Groutz A, Hasson J, Wengier A, et al. Third- and fourth-degree perineal tears: prevalence and risk factors in the third millennium. Am J Obstet Gynecol 2011 Apr;204(4):347.e1-347.e4. DOI: 10.1016/ j.ajog.2010.11.019.

4. de Leeuw JW, Struijk PC, Vierhout ME, et al. Risk factors for third degree perineal ruptures during delivery. BJOG 2001 Apr;108(4): 383-387. DOI: 10.1016/S0306-5456(00)00090-5.
5. Odent M. Birth under water. Lancet Lond Engl 1983 Dec 24; 2(8365-8366):1476-1477. DOI: 10.1016/S0140-6736(83)90816-4.

6. Cluett ER, Burns E. Immersion in water in labour and birth. Cochrane Database Syst Rev 2009 Apr;15(2):CD000111. DOI: 10.1002/14651858. CD000111.pub3.

7. Zanetti-Daellenbach RA, Tschudin S, Zhong XY, et al. Maternal and neonatal infections and obstetrical outcome in water birth. Eur J Obstet Gynecol Reprod Biol 2007 Sep;134(1):37-43. DOI: 10.1016/ j.ejogrb.2006.09.012.

8. Zanetti-Dällenbach R, Lapaire O, Maertens A, et al. Water birth, more than a trendy alternative: a prospective, observational study. Arch Gynecol Obstet 2006 Oct;274(6):355-365. DOI: 10.1007/s00404-0060208-1.

9. Pinette MG, Wax J, Wilson E. The risks of underwater birth. Am J Obstet Gynecol 2004 May;190(5):1211-1215. DOI: 10.1016/j.ajog.2003.12.007.

10. Lim KMX, Tong PSY, Chong Y-S. A comparative study between the pioneer cohort of waterbirths and conventional vaginal deliveries in an obstetrician-led unit in Singapore. Taiwan J Obstet Gynecol 2016 Jun;55(3):363-367. DOI: 10.1016/j.tjog.2016.04.012.

11. Mollamahmutoğlu L, Moraloğlu O, Ozyer S, et al. The effects of immersion in water on labor, birth and newborn and comparison with epidural analgesia and conventional vaginal delivery. J Turk Ger Gynecol Assoc 2012;13(1):45-49. DOI: 10.5152/jtgga.2012.03.

12. Nutter E, Meyer S, Shaw-Battista J, et al. Waterbirth: an integrative analysis of peer-reviewed literature. J Midwifery Womens Health 2014 Jun;59(3):286-319. DOI: 10.1111/jmwh.12194.

13. Edlich RF, Towler MA, Goitz RJ, et al. Bioengineering principles of hydrotherapy. J Burn Care Rehabil 1987 Dec;8(6):580-584. DOI: 10.1097/00004630-198711000-00031.

14. Thoeni A, Zech N, Moroder L, et al. Review of 1600 water births. Does water birth increase the risk of neonatal infection? J MaternFetal Neonatal Med Off J Eur Assoc Perinat Med Fed Asia Ocean Perinat Soc Int Soc Perinat Obstet 2005 May;17(5):357-361. DOI: 10.1080/14767050500140388.

15. Cortes E, Basra R, Kelleher CJ. Waterbirth and pelvic floor injury: a retrospective study and postal survey using ICIQ modular long form questionnaires. Eur J Obstet Gynecol Reprod Biol 2011 Mar;155(1): 27-30. DOI: 10.1016/j.ejogrb.2010.11.012. 